\title{
A TEORIA E A PRÁTICA NA FORMAÇÃO DE PROFESSORES DE GEOGRAFIA NA MODALI-DADE SEMIPRESENCIAL ${ }^{1}$
}

\section{THEORY AND PRACTICE IN THE DEVELOPMENT OF GEOGRAPHY TEACHERS THROUGH DISTANCE EDUCATION MODALITY}

\author{
Glaucio José Marafon ${ }^{1}$, Anercilia Martins ${ }^{1^{2}}$, Vanilda Teófilo ${ }^{1^{2}}$ \\ ${ }^{1}$ Universidade do Estado do Rio de Janeiro (UERJ), Rio de Janeiro, RJ, Brasil \\ ${ }^{2}$ Centro de Educação Superior a Distância do Estado do Rio de Janeiro (CEDERJ), Rio de Janeiro, RJ, Brasil
}

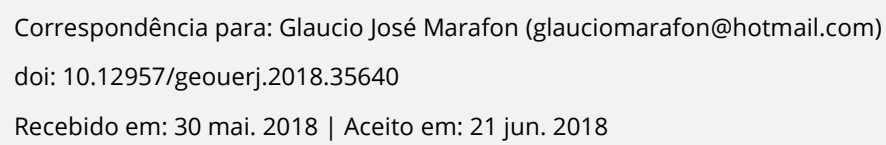

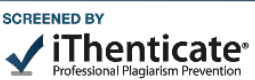

\section{RESUMO}

O presente trabalho relata a experiência realizada ao longo do curso de formação de licenciandos nas disciplinas de Teoria e Prática em Geografia no sistema semipresencial do curso de Licenciatura em Geografia da UERJ/CEDERJ. Objetiva-se destacar a importância da transposição didática especialmente em um curso na modalidade EaD, na forma como a entendemos, na qual o aprendizado não acontece de forma acidental, mas, ao contrário, requer planejamento e técnicas específicas, ocorrendo fora dos espaços convencionais de ensino, considerando que a comunicação se dá por meio de diferentes tecnologias. A metodologia foi alicerçada nas bases teóricas do construtivismo e do sociointeracionismo. A intenção é contribuir para uma melhor preparação dos licenciandos, para que eles atuem em um sistema de educação inclusiva, no âmbito do qual a pluralidade de subjetividades e saberes seja privilegiada, mesmo com a ciência das dificuldades e dos desafios a serem enfrentados no contexto de formação de professores.

Palavras-chave: educação a distância; transposição didática; processo ensino aprendizagem; formação de professores.

\begin{abstract}
This work presents an experience resulting from a course for Geography undergra-duates (future teachers) - teaching of Theory and Practice in Geography subject - in a bifacial system (physical attendance/on-line engagement) linked to the licentiate ma-jor in Geography of Rio de Janeiro State University (UERJ/CEDERJ) and through the guidance of the course coordinator. Insofar as the course developed, the idea of writing on the work being performed grew. The aim was to highlight the importance of the di-dactic transposition, especially in distance education modality as we understand it, meaning that learning does not happen accidentally; the other way round, it requires specific planning and techniques, for it occurs outside conventional educational spaces, its communication relies on different technologies. The methodology followed theo-retical assumptions of constructivism and sociohistorical psychology. The intention is to help improving the preparation of students to work in an inclusive educational system, that is to say, in a system that privileges the plurality of subjectivities and knowledge, even though teacher's education context poses challenges and difficulties.
\end{abstract}

Keywords: distance education; didactic transposition; teaching and learning process; teacher's education.

\section{INTRODUÇÃO}

\footnotetext{
${ }^{1} \mathrm{O}$ curso de Licenciatura em Geografia é ofertado pela UERJ, no âmbito do Consórcio CE-DERJ (Centro de Educação Superior a Distância do Estado do Rio de Janeiro), que é formado por sete instituições públicas de ensino superior - CEFET, UENF, UERJ, UFF, UFRJ, UFRRJ e UNIRIO - e conta, atualmente, com mais de 50 mil alunos matriculados em seus 15 cursos de graduação a distância 
As significativas transformações que ocorrem neste início de século, que se materializam na hegemonia do modo de produção capitalista, na postura neoliberal, na existência de um Estado mínimo e na globalização financeira possibilitada pelas redes telemáticas, indicam como a realidade do mundo atual é dinâmica e complexa. Essas profundas e rápidas transformações são justamente as que ocorrem em um mundo onde estão a requerer um saber geográfico crítico, pautado em um núcleo epistêmico balizado pelos fundamentos do pensamento geográfico e pelo compromisso social do professor de Geografia em interpretar a realidade.

Torna-se necessário, nessa perspectiva, levar em consideração, além dos aspectos da formação do mercado de trabalho, outras dimensões que se abrem a partir do saber geográfico, sobretudo no exercício da crítica, da convivência com as diferenças, da expressão livre e criativa, do trabalho coletivo que valoriza as experiências sociais já consagradas, do estímulo às descobertas e às reflexões como condições indispensáveis à formação do cidadão.

Neste início de século, o mundo passa por um conjunto dinâmico de transformações que se articulam nas escalas local, regional e global - novas tecnologias são incorporadas à sociedade e, muitas vezes, resultam em novos recortes de espaço e tempo que afetam a vida cotidiana das pessoas.

A ciência geográfica, enquanto área do conhecimento, procura identificar e analisar as escalas dessas transformações para, posteriormente, aplicar os resultados dessa investigação científica sistematizada à formação do professor de Geografia. Torna-se imprescindível apreender a noção de espaço geográfico, analisar a dinâmica de sua produção, o papel da sociedade nessa produção e na construção de sua trajetória, com a compreensão da realidade vivenciada.

Para entender o espaço, é necessário primeiro conhecê-lo e saber que, nesse processo, todos os homens encontram-se incluídos, visto que ao construirmos nossa história estamos formando o espaço geográfico. Nesse sentido, ao estudarmos a Geografia, é necessário partir do mais real possível, do mais próximo possível, procurando entender a realidade tal como ela se apresenta, seja do ponto e sua estrutura, seja na perspectiva de sua informação. Entretanto, em cima dessa realidade, é preciso 
teorizar, isto é, compreendê-la como expressão local/regional do conjunto do território. É preciso buscar caminhos, saber ser participante e abrir /encaminhar alternativas (CALLAI, 1993, p. 31).

O estudo da natureza deve ser pautado pela dimensão social, ou seja, a partir do ser humano enquanto um ser histórico. O espaço físico faz parte da compreensão da própria realidade e do seu espaço. Os elementos naturais (relevo, solo, vegetação, clima etc.) devem ser compreendidos no contexto em que vivem os homens, levando-se em conta o desenvolvimento tecnológico, e como são apropriados pela sociedade.

Destarte, é necessário que os alunos do ensino básico compreendam a Geografia como uma disciplina que os conduza a entender o mundo em que vivem e no qual todos são agentes na construção/transformação dele, pois, conforme aponta Rosa (2006, p. 20):

\footnotetext{
os programas de formação de professores cumprem um importante papel social, podendo contribuir para a inserção dos futuros professores na lógica da ordem social ou para promover a análise crítica da realidade com o objetivo de torná-lo melhor.
}

Para atender a essa premissa, no curso de Licenciatura em Geografia, na modalidade semipresencial, encontram-se oito disciplinas de Teoria e Prática em Geografia, que proporcionam, conjuntamente com as outras disciplinas do curso, essa reflexão. Dessa forma, o objetivo deste ensaio é o de relatar a experiência na formação dos licenciados do curso da UERJ/CEDERJ. Será descrito como se procede ao longo do curso na busca da formação de um profissional de Geografia atento à formação cidadã dos futuros professores.

\section{A formação de professores na modalidade semipresencial}

A implantação de um curso na modalidade semipresencial proporciona a interiorização da universidade e a inclusão de alunos que têm a possibilidade da realização de um curso superior. No Mapa 1, visualizamos a origem dos alunos matriculados em 2017.2. Observa-se que estão presentes na quase totalidade dos municípios fluminenses. 


\section{Procedência dos Alunos no Curso de Licenciatura Geografia UERJ/CEDERJ 2017}

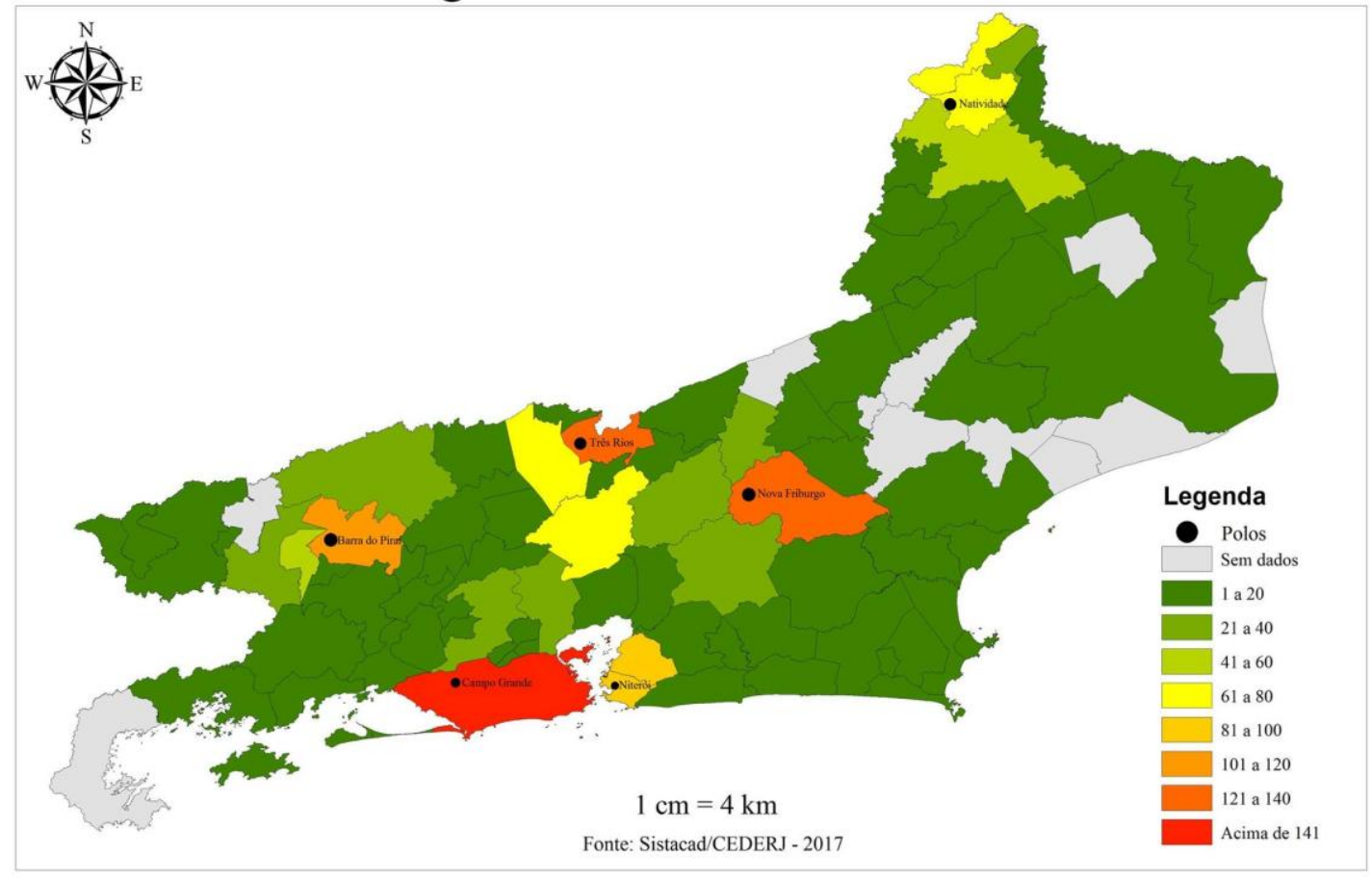

Figura 1. Procedência dos Alunos do Curso de Licenciatura em Geografia UERJ/CEDERJ Ano de 2017.

Destacamos que a origem dos alunos se vincula a praticamente todos os municípios do estado do Rio de Janeiro, com destaque para os municípios onde os polos que servem de suporte aos alunos do curso de Geografia estão localizados. Ainda que a Região Metropolitana apresente vários cursos presenciais, em instituições de ensino superior públicas e privadas, observa-se o elevado número de alunos delas oriundos. Isso se explica pela alta concentração populacional na RMRJ, pois cerca de $75 \%$ da população fluminense apresentam seu domicílio na referida região. Existem, em menor número, alunos oriundos dos estados vizinhos, tais como Minas Gerais e Espírito Santo. O perfil desses alunos remonta a um grupo com faixa etária mais elevada e que exerce atividades profissionais. Destarte, o curso na modalidade semipresencial proporciona uma oportunidade de formação em nível superior.

Assim, o aluno do curso de Licenciatura em Geografia, nessa modalidade, tem à disposição, para seus estudos, cadernos didáticos, guias de orientação, aulas na web (plataforma), tutorias presenciais (nos polos) e tutorias a distancia (fóruns e chats), além de atividades presenciais (avaliações, trabalhos de campos, semanas acadêmicas etc.). Esse conjunto de atividades proporciona a interação do aluno com 
os conteúdos e com professores e tutores para esclarecimento das dúvidas e reflexões sobre os temas propostos nas aulas.

Na busca de sentido, em função das múltiplas experiências vividas no ensino presencial, percebemos que trabalhar com a educação, qualquer que seja a modalidade, é um exercício constante de formação e, nessa direção, podemos afirmar que os saberes construídos e cultivados com uma grande quantidade de professores da escola básica e da universidade resultaram na luta pela conquista de condições que possam transformar a educação pública em inclusiva.

Bem sabemos que o emblemático sinal de um projeto de inclusão passa necessariamente pelo respeito às singularidades, particularidades e experiências daquele a que se destina. Esse novo paradigma pressupõe a criação de estratégias que apóiem a inserção social em que as experiências inclusivas deverão ser estimuladas e implementadas nos espaços educativos.

Certamente, uma forma de aprendizado e de ensino que permita o acesso crescente a oportunidades de aprendizado, projetando processos de aprendizagem e de ensino à altura dos desafios atuais, torna a educação a distância uma área extremamente instigante e desafiante. Entendemos a EaD como sistêmica e com um caráter multidisciplinar em que um conjunto de partes opera de forma integrada, favorecendo o processo de ensino e aprendizagem a distância, e, ainda, o aprendizado não acontece de forma acidental, mas, ao contrário, requer planejamento e técnicas específicas, ocorrendo fora dos espaços convencionais de ensino, considerando que a comunicação se dá por meio de diferentes tecnologias.

Se concordarmos com Matar (2014), ao dizer que a modalidade a distância descortinou um universo de possibilidades para a educação, tendo os avanços tecnológicos como um aliado dessa empreitada, vamos facilmente entender que foram eles que favoreceram a utilização das mais diferentes mídias como recurso pedagógico e que esse uso ajuda, sem dúvida, na construção de uma nova concepção de ensino e de aprendizado. 
Foi por esse caminho que conseguimos ver um tipo de movimento necessário e possível à pratica docente: um educador que recupera as tarefas pedagógicas procurando compreender o papel sociopolítico da educação e dos espaços educativos.

Há de se considerar que um tutor educador competente não é mais o que apenas domina o saber de sua disciplina, mas aquele cuja competência reside também na preocupação com a apreensão do conhecimento pelos alunos. Estamos pressupondo que existam novas perspectivas, novos recursos a serem acessados, buscando outros que permitam trabalhar. Aqui, já podemos afirmar que a convivência com as diferenças sempre representou um desafio para nós. Por essa razão, temos que unir esforços no sentido de "caminharmos e avançarmos em outras dimensões, especialmente as humanas e sociais" (LINHARES, 2002, p. 117).

Em nossas práticas, procuramos caminhar na contração dos modismos pedagógicos, muitas vezes rapidamente absorvidos, sem qualquer crítica, por parte daqueles que os adotam, buscando desenvolver uma linha consistente de trabalho, conforme nos ensina Mello (1998, p. 53) - uma questão que nos coloca, de imediato, diante do grande desafio de encontrar uma interlocução possível que permita olhar para os processos de aprendizagem e de ensino à altura dos desafios atuais, quando é sabido que pouco se vem cogitando acerca da construção do conhecimento (TEÓFILO, 2007).

É importante salientar que o advento da pós-modernidade trouxe constantes mutações e transformações para a sociedade, apresentando um horizonte de incertezas, com reflexos nos mais diferentes aspectos da vida humana. O principal impacto foi o descentramento do sujeito cartesiano isso desencadeou um novo olhar da ciência para a realidade cultural dos sujeitos, propondo uma tolerância de caráter sócio-histórico dos processos cognitivos e o direito à identidade cultural. É evidente que isso criou uma revolução nos estudos sobre a mente humana, com significativas repercussões nos espaços educativos, que nem sempre acompanharam tais mudanças.

Para deslocarmos da concepção de sujeito cartesiano racional e consciente, situado no centro do conhecimento, para uma concepção social, na tentativa de reconhecermos também o sujeito social, não só o cognitivo, achamos por bem nos apropriarmos de um outro quadro teórico que nos permitisse dar 
conta, de forma mais satisfatória, de incluir o maior número possível de alunos que pudessem acessar o saber científico.

Sentimos a necessidade, enquanto profissionais que atuam na modalidade EaD, de nos apropriarmos de um outro quadro teórico, pois uma vez trabalhando com a educação a distância, temos de deslocar uma unidade teórica para a multiplicidade de saberes, o que exige uma prática docente reflexiva, alicerçada em um entendimento e uma compreensão de mente e de saber que considerem a heterogeneidade, uma concepção de sujeito social que precisa acessar o saber científico.

Trabalhar com EaD é atuar com as diferenças, e isso significa levar em consideração o significado e o sentido dos valores culturais dos nossos aprendizes licenciados, tomando-os como objetos de conhecimento específicos, que influenciam o processo educativo formal e que são referenciais concretos, via única de compreensão dos conhecimentos a serem abordados e trabalhados nas salas de tutoria.

O sistema de tutoria tem sido fundamental no processo de ensino-aprendizagem, e, nesse sentido, tem sido feito um investimento para que o tutor construa um pensamento inclusivo, pensando numa outra lógica para o curso de formação de professores de Geografia. Tal lógica é diferente daquela a que estamos acostumados e que tem gerado o descrédito dos agentes educativos, uma prática que vem buscando uma melhor compreensão das variáveis que incidem - direta ou indiretamente - nas nossas práticas marcadas pelo respeito à pluralidade, o que implica buscar fatores para além das fronteiras da universidade. Além dos cursos de formação, mais técnicos, proporcionados pelo consórcio CEDERJ. A equipe de coordenação do curso possibilita, em encontros regulares, uma formação complementar para que os tutores possam desempenhar seu papel de forma a contribuir na formação dos licenciandos.

A partir dessas preocupações, foi traçada uma metodologia que expressa a ideia de uma transposição didática e que veio a se constituir formalmente no nosso foco de trabalho.

A transposição didática de que nos falam autores como Perrenoud (1993, p. 25), Chevallard (1998) e Almeida (2011) foi por nós assumida e entendida como a possibilidade de encurtar o caminho entre o conhecimento científico e o conhecimento desenvolvido nos espaços educativos, pois o distanciamento 
entre teoria e prática inviabiliza a possibilidade de se entender o espaço educativo como um espaço de construção, articulador de diferentes conhecimentos, no qual a teoria ancora uma prática diariamente refletida num movimento dinâmico e contínuo de construção e reconstrução (TEÓFILO, 2007).

Antes da descrição própria do trabalho realizado nas disciplinas de teoria e Prática Geográficas (TPGs), ressaltamos que as estratégias são implementadas de forma processual, sendo pensadas, repensadas e reestruturadas ao longo do percurso, levando em consideração as características especificas dos alunos e do contexto dos licenciandos (ALMEIDA, 2011).

É possível afirmar que o trabalho desenvolvido no curso de Geografia exprime a idéia sugerida por Almeida (2011, p. 25), de que é preciso "edificar uma concepção própria de transposição didática" concebemos o educador (tutor) e o aluno (licenciando) como construtores de uma pluralidade de saberes e pesquisadores de sua prática, procurando implementar práticas significativas e inovadoras.

\section{A teoria e a prática na formação dos profissionais de Geografia no curso semipresencial da UERJ/CEDERJ}

O grupo de Teoria e Prática Geográficas (TPGs) tem se esforçado em busca de uma revisão constante dos seus princípios, fundamentos e práticas, trabalhando com a pedagogia dialógica, a caminho da concretização de um projeto, o qual acreditamos ser verdadeiramente inclusivo.

A disciplina Teoria e Prática em Geografia (TPG) é oferecida em todos os períodos do curso e pretende realizar a transposição entre o saber teórico oferecido pela universidade e a prática do docente em sala de aula. Como a disciplina é disponibilizada nos oito períodos regulamentares do curso, há uma sequência na apresentação de suas atividades, de acordo com o nível de aprendizagem que se espera para o graduando em cada fase de sua vida acadêmica.

Para Mattar (2014, p. 23), o que determina o sucesso ou o fracasso de projetos de EaD ocorre em função “do público-alvo, do desenho pedagógico do curso, das atividades propostas e de outras 
variáveis". À medida que o curso foi se desenvolvendo, foram sendo implementados e disponibilizados diferentes recursos.

Entendemos "recursos" como meios tecnológicos lançados pelo educa-dor, objetivando complementar e, portanto, facilitar o processo de construção do conhecimento, sendo um componente do ambiente de aprendizagem que exige conhecimento técnico e pedagógico do educador, uma vez que funciona como um estímulo à aprendizagem, tendo uma função, sem dúvida, de extrema importância.

\begin{tabular}{|l|l|}
\hline Atividades & Metodologias \\
\hline Discussão de textos & Por meio de fóruns \\
\hline Leitura de textos & Individual, com possibilidade de comentários \\
\hline Videotutorias & $\begin{array}{l}\text { Possibilidade de interação entre tutor e alunos de } \\
\text { polos diferentes }\end{array}$ \\
\hline Atividade online & $\begin{array}{l}\text { Desenvolvimento da articulação de comentários a } \\
\text { partir da análise de textos }\end{array}$ \\
\hline Produção de textos & Mediante envio de arquivos \\
\hline
\end{tabular}

Quadro 1 Atividades desenvolvidas em EaD e seus recursos, por meio da Plataforma Moddle: Fonte: Plataforma CEDERJ, 2017

Nas disciplinas de Teoria e Prática em Geografia, nossa preocupação na escolha dos mecanismos baseia-se na concepção de que tenham um potencial comunicativo e interativo, considerando-os como verdadeiro suporte à aprendizagem, visto serem "material de apoio ao processo" de construção do conhecimento (GOUVEIA e OLIVEIRA, 2006, p. 86).

Assim, um recurso adequado propiciará a interação propugnada por Piaget (1998) e/ou o auxílio à formalização dos conceitos, como nos ensina Vygotsky (1986), viabilizando o acesso à informação e criando, assim, um espaço descrito por Levy (1998) como ciberespaço, em que tutores e alunos “interagem, cooperam e aprendem juntos" (VALENTE e MORAN, 2011, p. 24). 
Todavia, quando olhamos para nossa experiência com os alunos em sala de tutoria, constatamos que temos ambientes ricos em aprendizagem com materiais elaborados - onde procuramos inovar, testar e experimentar -, como links, texto de apoio, além de uma estrutura física nos polos - bibliotecas e laboratórios - e encontros com tutores presenciais para reflexões acerca dos conteúdos veiculados nas diferentes disciplinas.

A articulação desse saber acadêmico/científico nem sempre é de fácil entendimento, principalmente quando o docente leciona nos anos iniciais do segundo segmento do ensino fundamental, no qual o aluno não está preparado para a aquisição de conhecimentos de forma meramente abstrata. Dessa forma, ancoramo-nos nos estudos de Piaget.

Esse pensador foi um dos estudiosos da questão da origem e formação da gênese do conhecimento, sendo inegável sua contribuição no sentido de melhor fundamentar as práticas pedagógicas. Sua visão de aprendizagem e de desenvolvimento e a forma como esses dois processos interagem interessou-nos sobremaneira, cabendo destacar alguns conceitos significativos dessa matriz conceitual, que procuramos utilizar em nossa prática docente.

Diante dessa visão, podemos inferir que as atividades lúdicas, concretas e, de certa forma, sequenciais devem ser apresentadas e trabalhadas de modo diferenciado, tendo em vista o perfil dos licenciandos. Temos, como exemplo, o trabalho desenvolvido sobre a percepção do espaço, que exige como prérequisito o conhecimento da percepção de vizinhança.

Partimos, então, propondo atividades que respeitem os recursos estruturais dos alunos, a fim de lhes permitir a assimilação dos conteúdos, com a preocupação de que façam sentido. Para tanto, nosso ponto de partida é a realidade do aluno (conhecimento empírico) caminhando em direção à construção dos conceitos (conhecimento conceitual) (CHIAROTTINO, 1992).

Nosso objetivo, a partir desse momento, é apresentar a metodologia trabalhada em cada uma das etapas. 
Teoria e Prática em Geografia I objetiva levar o graduando a se aproximar do conceito de transposição didática, fazendo com que construa a relação teoria/prática por meio da realização de um trabalho a ser enviado pela plataforma de ensino Moddle. Os artigos acadêmicos são apresentados, e sugere-se a leitura de revistas vinculadas a sua área de estudo. Procura-se, nesse momento, mesmo que de um jeito informal, desenvolver um arcabouço teórico neste licenciando que acaba de concluir a Educação Básica ou que está se reintegrando, após alguns anos de afastamento do sistema de ensino.

O estudo do meio torna-se nosso principal tema, e procuramos enfatizar para o futuro docente sobre a necessidade de trabalhar com a realidade do educando. Nesse momento, ancoramo-nos em Costella e Schäffer (2012, p. 53), que afirmam:

\footnotetext{
O estudo do lugar e o discernimento, pelo aluno, de que pertence a ele favorecem a compreensão de sua identidade. Um aluno é único, mas ao mesmo tempo, é o resultado de suas relações. Ele se reco-nhece quando compreende o que o envolve, as relações ali presentes e o processo, a continuidade do lugar. Quando, em sala de aula, insistimos em ensinar Geografia sem reconhecer a geografia do lugar do aluno, sacrificamos uma fase do reconhecimento de relações.
}

Tomamos como ponto de partida os conhecimentos veiculados nas disciplinas iniciais do curso, como: Climatologia Geográfica, Geologia Aplicada à Geografia, Cartografia Básica e Espaço, Natureza e Sociedade, vinculando-as ao estudo do meio, ou seja, ao ambiente de vivência e convivência, trabalhando com a noção de lugar, espaço e tempo, o que nos permite vivenciar a "transposição didática” (CHEVALLARD, 1998).

Corroborando com Costella e Schäffer (2012), faz-se importante o processo de alfabetização cartográfica para que possa realizá-lo com o discente. As noções de espacialidade, ao se trabalhar com a disciplina Cartografia, são apresentadas, e procura-se, também, levar o graduando a pensar sobre a importância do estudo do meio (local) em consonância com o meio tecnológico, em que o lugar se relaciona com o global e suas representações.

Como proposta de atividade para a presente etapa, o graduando deve montar uma atividade com as disciplinas do período em que o conteúdo acadêmico apresentado possa ser utilizado em suas aulas, por 
meio de um planejamento no qual são elencados objetivos, conteúdo, material didático, desenvolvimento/metodologia e avaliação.

Teoria e Prática em Geografia II, por sua vez, apresenta o trabalho de campo como fator primordial no ensino de Geografia, visto que, ao se pensar o espaço - ambiente de mutações e embates sociais -, há necessidade de o aluno "viver" o que está sendo estudado. A partir desse contato, abre-se a possibilidade de formar cidadãos críticos, com potencialidades para análise de forma concreta/real. As atividades de campo poderão facilitar a aquisição de conhecimentos referentes a diferenciadas facetas da Geografia - física ou humana -, revelando-se, assim, uma estratégia pedagógica de excelência para desenvolvimento da aprendizagem. A proposta apresentada nessa fase se uti-liza dos conhecimentos veiculados nas disciplinas de Geomorfologia Geral, Geografia do Ciberespaço e Geografia da População.

A partir das disciplinas elencadas, propõe-se ao graduando que, a partir de uma atividade de campo realizada em seu próprio município, ele elabore um roteiro que possa ser trabalhado com alunos do segundo segmento do ensino fundamental ou médio. Esse roteiro deve possuir algum tipo de representação cartográfica, e o formato do texto já deve estar como o de um pequeno artigo acadêmico. Objetivamos, nessa fase, iniciar a construção da formação do professor/ pesquisador.

Como nos ensina Piaget, conhecer significa organizar, estruturar e explicar, mas isso a partir do vivenciado (experimentado). Essa é, sem dúvida, a questão fundamental dessa teoria. Conhecer não implica tão somente explicar ou viver, mas é um processo que tem como ponto de partida a vivência, a experimentação (uma ação sobre o objeto do conhecimento).

Ainda nessa perspectiva, para Marafon (2015): "o trabalho de campo, como técnica de análise, pode ser realizado em qualquer paisagem, seja rural ou urbana, e utilizado para a obtenção de informações sobre a importância das relações”. 
Ancorados na perspectiva da teoria piagetiana, não basta explicar como se dá o conhecimento de um adulto, mas perceber as condições necessárias para que se chegue ao conhecimento, que depende, basicamente, da ação recíproca organismo-meio, em que as trocas são responsáveis pela construção da própria capacidade de conhecer; sem elas, essa capacidade não se constrói, não ocorrendo, portanto, mudança de comportamento (ENDERLE, 1987).

Em Teoria e Prática em Geografia III, são apresentados os recursos didáticos, procurando estabelecer as diferenças entre metodologia/procedimentos e recursos didáticos, pois há uma tendência de se confundir o que é a prática do educador com o instrumento pedagógico a ser utilizado.

A partir de conhecimentos anteriores e leituras propostas sobre o tema - recursos didáticos, sua importância e utilização - e supondo que o licenciando já o tenha assimilado a conceitos pedagógicos, solicitamos que seja construído um texto acadêmico.

Resgatando os conceitos de Piaget, é possível constatar, nessa etapa, os dois processos que se complementam na aprendizagem; a saber: assimilação e acomodação. A assimilação ocorre quando o aprendente imprime uma determinada ação para solucionar uma dada situação-problema e utiliza-se de uma estrutura mental já formada e, portanto, a nova situação é incorporada e assimilada a um sistema já pronto. Trata-se de um repertório comportamental ou mental que se atualiza para dar conta de uma circunstância.

Já a acomodação ocorre quando ao tentar solucionar determinada situação-problema, o sujeito se utiliza de uma estrutura mental que já possui, mas um novo elemento é adicionado, incorporado e, em consequência, assimilado àquela estrutura até então existente, atualizando seu repertório comportamental ou mental em uma situação determinada.

Nesse momento, enfatizamos também o uso de novas tecnologias e o trabalho de forma interdisciplinar com as variadas linguagens. Temos, como exemplo, as experiências que podem ser realizadas de forma concomitante ao ensino de biologia ou química, ao se trabalhar com conteúdos voltados à área de 
pedologia. Outros exemplos são as charges, histórias em quadrinhos ou dramatizações com auxílio de professores de língua portuguesa ou artes.

Nessa fase, as disciplinas do curso enfatizadas são: Geomorfologia Continental, Geografia da População do Brasil e Geografia Agrária. O objetivo, nesse processo, é destacar o papel do docente como mediador e não apenas como apresentador e expectador.

É interessante frisar que não há crítica à apresentação de aulas com recursos dinâmicos dos slides ou ao desenvolvimento da pesquisa e à autonomia estudantil, pois sabe-se que, na realidade da sala de aula, o docente assume variados papéis. O que se destaca e se incentiva, nesse momento, é a necessidade de apropriação dos diferentes recursos a serem utilizados.

Ao se enfatizar o uso de recursos didáticos variados e a importância das novas tecnologias, há uma preocupação de que o licenciando tenha percepção das diferentes realidades encontradas nas instituições de ensino e, assim, possa fazer suas adaptações e também ser capaz de realizar suas produções. Para Mello e Angeloni (2014, p. 789), "no entanto, a sala de aula é o espaço que o professor tem para contribuir no esforço coletivo dos educadores que se preocupam em buscar uma educação que seja capaz de superar seu caráter reprodutivista”.

Recorremos, novamente, à construção do conhecimento em Piaget, que nos ensina que a adaptação é resultado dos processos complementares de assimilação e acomodação. Eles estão presentes em todas as nossas ações durante toda a nossa vida e dificilmente ocorrem em separado, pois nunca uma situação ou objeto é exatamente igual a outro já conhecido (a).

A análise do livro didático é realizada em Teoria e Prática em Geografia IV. Sua utilização traz percepções bem diferenciadas, principalmente quanto ao seu real objetivo e sobre a adaptação aos currículos dos estados e municípios. Reforçando esse aspecto, Pontuschka, Paganelli e Cacete (2009, p. 343) afirmam que: "O Brasil é um país de grande extensão territorial constituído por realidades e culturas muitos diferentes, que os conteúdos do livro didático não têm condições de abarcar". 
Reforçamos, nessa etapa, o papel do livro didático como instrumento auxiliar ao processo de ensinoaprendizagem, pois, como sinaliza o MEC nos guias sobre os livros didáticos, avaliados e disponibilizados para os professores, eles podem servir como material didático de apoio e não como guia para o trabalho com os alunos. Destarte, o livro didático serve como um suporte aos professores e alunos no trabalho com os temas de Geografia. Baseados nas fichas de avaliações de tais livros e disponibilizados nos Guias, orientamos os alunos a efetuarem uma análise das obras para que façam uma escolha consciente e técnica do livro adequado às suas necessidades como profissional de geografia.

Nesse contexto, na disciplina que propõe a análise de capítulos de livros didáticos, sugerimos ao graduando que apresente, inicialmente, as diferentes abordagens, e que após a escolha de um livro, entre os anos de escolaridade (segundo segmento do ensino fundamental e ensino médio), realize uma análise sobre a apresentação dos conteúdos de uma das disciplinas do $4^{0}$ período.

A referida análise deve ser pautada também no Plano Nacional de Livros didáticos (PNLD), com ênfase nas disciplinas que estão sendo veiculadas no período em questão. A saber: Geografia e Sensoriamento Remoto, Geografia Econômica e Geomorfologia Costeira.

A disciplina Teoria e Prática em Geografia V se refere ao trabalho com representações, que se apresenta como arcabouço necessário para o a construção da noção de espaço. As atividades cartográficas devem ser enfatizadas desde o início do processo de aprendizagem, levando-se em consideração a leitura que cada educando faz da paisagem. Aprender a "ler" e "interpretar" o espaço geográfico faz parte do processo de desenvolvimento crítico-social, e a referida leitura pode ser estimulada de formas diferenciadas, enfatizando-se, mais uma vez, os anos de escolaridade do educando. Nessa fase, é importante que "ao refletirmos sobre o Espaço de Representação na escola podemos vislumbrar diversas perspectivas, como: a representação espacial construída pelos educando e educadores [...]" (KOZEL TEIXEIRA, 2006, p. 1). 
"A leitura pode partir de imagens e mapas dos locais do mundo confron-tando com o local, mas também pode partir da análise do espaço concreto e próximo" (CALLAI; ANDREIS, 2013, p. 11). Nessa fase, priorizamos a produção de um artigo, tomando principalmente como referência o município do licenciando, ou seja, o estudo de alguma área e as respectivas representações.

Por sua vez, em Teoria e Prática em Geografia VI, propomos aos licenciandos a construção de um projeto didático que tome como ponto de partida a sua vivência escolar. O graduando, ao analisar a escola onde realiza o estágio supervisionado, verifica as reais possibilidades para o desenvolvimento de um projeto a partir de uma problemática existente e tendo como foco as disciplinas cursadas no período. Também sugerimos a eles a articulação, no projeto, de atividades que despertem o interesse do educando, pois, como nos ensina Rego, Castrogiovanni e Kaercher (2007, p. 44), "os ensinos fundamentais e médios devem ser acima de tudo, desafiadores, capazes de despertar o interesse dos alunos para a resolução de problemas que a vida apresenta”.

Neste momento, não é nossa intenção desenvolver uma análise exaustiva acerca da teoria de Vygotsky (1989, 1991, 1992) e também não pretendes-mos trazê-la aqui como uma contraposição à teoria piagetiana, mas é com base nas suas concepções que pretendemos trazer a importância do meio na estruturação das condutas do sujeito e na formação do conhecimento, aspectos que assumiram um lugar de destaque na teoria.

Nessa etapa da disciplina, chegamos ao processo de formação e de construção dos conceitos e, com base nesse teórico, encontramos as explicações acerca de como eles se transformam ao longo do desenvolvimento: de início, a linguagem se apresenta como um meio de comunicação entre as pessoas, e à medida que o sujeito vai se desenvolvendo, o pensamento vai se organizando, chegando a se tornar uma função mental interna. Os significados fornecidos pelo grupo ao qual pertence vão sendo internalizado pelo sujeito nas trocas, e, por meio das interações sociais, o mundo (a fala) exterior se converte em interior (VYGOTSKY, 1991). 
Aprendemos com Vygotsky que a construção e o desenvolvimento dos conceitos é um processo longo não linear e muito menos simples - e sua trajetória genética aponta para duas raízes independentes que mais tarde se cruzam e se unem num momento avançado do desenvolvimento, emergindo desse processo qualitativo os "conceitos genuínos" (OLIVEIRA, 1992) que envolvem um sistema de relações e generalizações (contidas nas palavras) que ocorrem nas trocas entre o homem e a cultura.

Assim, o que importa na presente discussão é que, para essa teoria, é a cultura que baliza as condições de aprendizagem dos sujeitos: "Os sujeitos aprendem e se desenvolvem nas relações produzidas numa determinada cultura" (OLIVEIRA, 1992) e não como se pensava, ou ainda se pensa, ou seja, por meio de um discurso unificador.

Se levarmos em conta o fato de que o aprendizado desperta vários processos internos de desenvolvimento, porque se inicia muito antes do ingresso do aluno na vida escolar; e se tomarmos como ponto de partida que "qualquer situação de aprendizagem com a qual nos defrontamos no espaço escolar tem sempre uma história prévia" (VYGOTSKY, 1991, p. 93), essas considerações indicam o quanto se torna infrutífera "a idéia de que se aprende algo de forma rápida e mecânica - concepção pregnante nos espaços educativos" (TEÓFILO, 2007, p. 142).

Nessa direção, a hipótese de que os conceitos científicos e espontâneos não se desenvolvem em direção contrária, mas se interconectam ao longo do desenvolvimento, ganha relevância para nosso trabalho, porque corrobora afirmativas anteriores, quando sinalizamos que o educador, para desempenhar bem o seu papel, terá que desafiar a construção de novos conhecimentos, necessitando tomar os conceitos espontâneos, do cotidiano (o que o aluno já sabe) como ponto de partida.

Uma outra perspectiva que se abre com essa teoria e que nos permite estabelecer uma relação com a nossa prática docente refere-se à oportunidade de um redirecionamento de nosso olhar para os alunos como ativos e interativos no seu processo de conhecimento. O saber é compartilhado nas relações estabelecidas entre o sujeito e o objeto do conhecimento - princípio confirmado na nova direção do social para o individual, criando um modelo de ação comunicativa pura (CHAUI, 2002). 
É nessa perspectiva que procuramos redimensionar os conceitos científicos, mudando-os de papel e de lugar, enquanto ampliadores de novas competências, posto que interconectados com os conceitos espontâneos (do cotidiano, da experiência), passaram a indicar uma prática que, como ressaltada algumas vezes, procura se basear em um novo entendimento de sujeito, de educação, de desenvolvimento e de aprendizagem.

Teoria e Prática em Geografia VII apresenta como proposta a produção de um projeto de pesquisa. Entendendo o espaço da tutoria como um espaço de formação e movidos pela questão da relação entre o educador e a pesquisa, chegamos ao conceito de "professor pesquisador", inspirados em Schon (1983), o precursor da idéia de "professor reflexivo".

Parece clara a articulação pesquisa e formação apontada por Ludke (2001), uma constatação que vem exigindo uma busca por caminhos que ajudem a melhorar a ação docente, em uma reflexão contínua sobre as práticas desenvolvidas nos diferentes períodos dessa disciplina.

Argumenta-se, nesse momento, sobre a necessidade do professor como pesquisador e o desenvolvimento de sua autonomia, pois "apesar da importância dessa questão, persiste ainda a idéia de que o professor da escola básica não necessite pesquisar" (PONTUSCHKA, N. N.; PAGANELLI, T. I; CACETE, 2009, p. 96).

Propondo ao licenciando um trabalho com estrutura dialógica e colaborativa no contexto de uma prática reflexiva - acreditamos ser esse, sem dúvida, um caminho de formação de um futuro educador reflexivo -, direciona-se o projeto de pesquisa para o tema do trabalho de conclusão do curso, visando demonstrar para o licenciando que "investigar é pesquisar e que a pesquisa deve desenvolver o aprender a pensar [...]” (PONTUSCHKA, N. N.; PAGANELLI, T. I.; CACETE, 2009, p. 96).

Na etapa final (TPG VIII), objetiva-se a produção de um artigo acadêmico cuja temática se baseia no currículo mínimo e em sua articulação nas redes de ensino (Estadual e Municipal). 
Procuramos desenvolver uma discussão embasada na análise histórica do currículo de Geografia, perpassando pelas variadas fases, como a Lei de Diretrizes e Bases da Educação, nㅜ 5.692, em 1971, que dava ênfase aos Estudos Sociais. A partir desse momento, procuramos verificar as abordagens realizadas com os movimentos de renovação da Geografia e com relação às diretrizes dos Parâmetros Curriculares Nacionais.

O aluno deverá fazer uma análise crítica sobre a proposta curricular do estado do Rio de Janeiro, focando nos anos de escolaridade dos ensinos fundamental e médio.

A perspectiva aqui defendida é a de que tanto o licenciando como o tutor educador são sujeitos do conhecimento e, portanto, produtores de saberes produzidos no espaço de tutoria e são eles que vão permitir ao profissional de educação aperfeiçoar suas práticas.

Vimos com Tardif (2002, p. 223) que as competências profissionais estão diretamente ligadas às “capacidades dos licenciandos/alunos de racionalizar suas próprias produções, de criticá-las, de revisálas e de objetivá-las [...]".

Esse encaminhamento no processo de formação de professores está em consonância com Cavalcanti (2006, p. 33).

o primeiro ponto é colocar o aluno como centro e sujeito do processo de ensino, para a partir daí refletir sobre o papel do professor e da Disciplina, que são elementos igualmente integrados no contexto didático.

No processo avaliativo, considera-se a preocupação em criar um procedimento que tomasse como ponto de partida a reflexão acerca do lugar que a avaliação deve ocupar na modalidade a distância, não perdendo de vista que é a "relação intrínseca entre avaliação e aprendizagem, o que, certamente, impõe-nos a busca de uma coerência entre ambas" (TEÓFILO, V. M. S.; FILHO, D. S, 2013, p. $185)$. 
Tomando como premissa básica que "avaliar é para agir" (PERRENOUD, 1999, p. 32), uma solução interessante encontrada e que vem trazendo um resultado eficiente e eficaz é o trabalho com o aluno no sentido do estímulo à compreensão dos textos, à escrita nas normas acadêmicas e às atividades que permitem ao aluno se expressar e produzir conhecimento a partir da sua realidade, pois:

\footnotetext{
o desenvolvimento de um modo de pensar geográfico mais amplo e abstrato requer, portanto, a formação de conceitos pelos alunos. O trabalho com o conteúdo geográfico, para que ele se torne ferramenta do pensamento, implica a busca de significados e sentidos dados pelos discentes aos diversos temas trabalhados em sala de aula, considerando a experiência vivida por eles (CAVALCANTI, 2006, p. 33).
}

Para tanto, a preocupação em veicular conhecimentos significativos, ou seja, aqueles de extrema importância e relevância para os alunos, tem sido a tônica do trabalho, entendendo a equipe de tutores e coordenação, que tanto o conteúdo quanto a forma como vem sendo disponibilizados devem ser sistematicamente avaliados.

\section{CONSIDERAÇÕES FINAIS}

O desafio na formação de um profissional de geografia, crítico e cidadão, na modalidade semipresencial, está posta, uma vez que essa modalidade democratiza o acesso de um contingente maior ao ensino superior, no caso de um consórcio de universidades públicas. Tais democratização e oportunidade de acesso são demonstradas por meio das origens dos alunos matriculados no curso de Geografia.

A preocupação quanto à formação desses profissionais nos levou a proposição de oito disciplinas de Teoria e Prática em Geografia, que consistem em um conjunto de abordagens que visam proporcionar ao licenciando reflexões e práticas que o tornem um profissional capaz de formar alunos, com um viés crítico, e que seja capaz de proporcionar àqueles do ensino básico uma abordagem cidadã da ciência geográfica. Além disso, que ao mesmo tempo que tenha sólida formação científica, tenha também condições de efetuar uma transposição desses conteúdos de forma a auxiliar os discentes a entenderem o espaço e a sociedade em que vivem. 
Dessa forma, conjugando os aportes conceituais de Piaget e Vygotsky com a nossa realidade, temos a clareza, por um lado, de que a heterogeneidade é imprescindível para as interações sociais, porque imprime a possibilidade de trocas de repertório, de confrontos e de ajuda mútua, fatores fundamentais para a ampliação das capacidades individuais.

Quando concordamos que as ferramentas ou recursos necessários e propulsores do desenvolvimento dos sujeitos e, portanto, garantidores de mudanças, são fornecidos pela cultura, a condição dos tutores de tomarem a experiência de vida dos alunos como ponto de partida em suas práticas revela a possibilidade de concretude de uma prática docente inclusiva, sendo inquestionável a contribuição de Vygotsky na viabilização de uma maior e melhor inserção dos alunos de EaD.

Tendo em vista a pluralidade de alunos (licenciandos) que transitam nos diferentes polos e no ambiente da plataforma, entendemos que nossas práticas deverão ter como ponto de partida a experiência dos alunos, levando em conta seus diferentes ritmos, comportamentos, experiências, trajetórias pessoais uma prática que procura embutir uma outra visão de aluno (ativo e interativo) e de mundo (complexo, em constantes transformações), melhor adequada ao contexto de EaD.

Todas essas considerações apontam para um espaço que propicia a oportunidade de reconstrução do vivenciado e aprendido, a fim de que o futuro educador não tome os conhecimentos como rituais, cópias com imitações mecânicas de modelos fornecidos.

À equipe de formação, aos professores e tutores formadores cabe, enquanto mediadores do processo ensino-aprendizagem, a função de ampliadores de repertórios dos futuros educadores - os conhecimentos internalizados serão orientados e reorientados de forma a tornar o comportamento e a ação profissional desses futuros educadores mais dinâmicos e criativos.

Não temos dúvida de que é nesse espaço de superação de uma concepção tradicional de aluno e da insurgência teórica - protagonizada por Vygotsky - que conseguiremos dar conta de uma educação verdadeiramente inclusiva e de um licenciando, futuro educador e agente de educação social. 
Destarte, busca-se a valorização ampliada dos futuros profissionais de Geografia para que cumpram suas funções sociais e que possam atuar na mediação da construção do conhecimento, sobretudo na atualidade marcada fortemente pela globalização, em que se amplia uma homogeneização do espaço e, contraditoriamente, ampliam-se as desigualdades sociais.

A formação de profissionais de geografia, na modalidade semipresencial, tem o cuidado de preservar o papel do tutor educador, que é o centro do processo, e assim acompanhamos e observamos a atuação dos professores, orientando sua prática pedagógica em princípios que privilegiem o contexto de experiência dos alunos/licenciandos, cujo enfoque sociocultural é contemplado nas situações de aprendizagem e cujas trocas entre os diversos ambientes são levadas em consideração, assim como a multiescalaridade presente no cotidiano, no qual o local e global estão intimamente relacionados. As atividades realizadas nas oito disciplinas de Teoria e Prática em Geografia possibilitam a formação desse profissional em consonância com a atualidade em que vivemos.

\section{REFERÊNCIAS}

ALMEIDA, G. P. Transposição didática: por onde começar? 2 ed. São Paulo: Cortez, 2011.

CALLAI, H. C.; ANDREIS, A. "Com o mundo nas mãos: a geografia na educa-ção básica”. Rev. Geográfica de Valparaíso (En línea). Valparaíso (Chile), n. 47, p. 03-12, 2013.

CAVALCANTI, L. S. (Org.). Formação de professores: concepções e práticas em geografia. Goiania: Editora Vieira, 2006.

CHEVALLARD, Y. La transposición didáctica: del saber sabio al saber enseñado. Buenos Aires: Aique, 1991.

CHAUI, M. A vida e o ofício dos professores: formação continua, autobiografia e pesquisa em colaboração. São Paulo: Escrituras, 2002.

CHIAROTTINO, Z. Psicologia e epistemologia genética de Jena Piaget. São Paulo: EPU, 1992.

COSTELLA, R. Z.; SCHÄFFER, N. O. A geografia em projetos curriculares: ler o lugar e compreender o mundo. 1. ed. Erechim: Edelbra, 2012. v. 1.

ENDERLE, C. Psicologia do desenvolvimento: o processo evolutivo da criança. 2 ed. Porto Alegre: Artes Médicas, 1987.

GOUVÊA, G.; OLIVEIRA, C. I. Educação a distância na formação de professo-res: viabilidades, potencialidades, limites. Rio de Janeiro: Vieira \& Lent, 2006. 
KOZEL TEIXEIRA, S. "Geografia, representação e ensino: um olhar sobre a dimensão conceitual”. In: I Colóquio Nacional do Núcleo de Estudos em Espaço e Representação, 2006, Curitiba. Anais do I Colóquio Nacional do Núcleo de Estudos em Espaço e representação. Curitiba: Editora da UFPR, 2006, v. 1, p. 45-58.

LINHARES, C.; LEAL, M. C. (Orgs.). Formação de professores, uma crítica à razão e à política hegemônicas. Rio de Janeiro. DP\&A, 2002.

LUDKE, M. (Coord.). O professor e a pesquisa. Campinas: Papirus, 2001.

MARAFON, G. J. "O trabalho de campo como um instrumento de trabalho para o investigador em geografia agrária". In: Cesar De David; Carmen Wizniewsky. (Orgs.). Agricultura \& Transformações socioespaciais. 1 ed. Santa Maria: Evangraf/Jadeeditora, 2015, v. 1, p. 26-46.

MATTAR, J. Guia de educação a distância. São Paulo: Cengage Learning, 2014.

MELLO, M. C. O.; ANGELONI, R. Z. "O lúdico e a dialógico no ensino de Geo-grafia: uma proposta para a prática pedagógica". Boletim Campineiro de Geo-grafia, v. 4, p. 487-497, 2014.

OLIVEIRA, E. S. G.; COSTA, M. A. "Avaliação dos cursos de licenciatura da UERJ: do espelho ao buraco da fechadura". In: Formação de professores na UERJ: memória, realidade atual e desafios futuros. Rio de Janeiro: Quartet, 2001.

PERRENOUD, P. Práticas pedagógicas, profissão docente e formação; pers-pectivas sociológicas. Lisboa: Dom Quixote, 1993.

PONTUSChKA, N. N.; PAGAnELli, T. I.; CACETE, N.H. Para ensinar e a-prender geografia. São Paulo: Cortez, 2009. $383 \mathrm{p}$.

REGO, N.; CASTROGIOVAnNI, A. C.; KAERCHER, N. A. (Orgs.). Geografia, práticas pedagógicas para o ensino médio. 3. ed. Porto Alegre: Grupo A, 2017. v. 1.

SCHON, D. A. Educando o profissional reflexivo: um novo design para o ensino e a aprendizagem. Porto Alegre: Artmed, 1998.

TARDIF, M. Saberes docentes e formação profissional. Petrópolis, RJ: Vozes, 2002.

TEÓFILO. V. M.S. Verdade e inclusão: perspectivas na formação dos novos professores. Tese (Doutorado em Educação) Programa de Pós-Graduação em Educação. Rio de Janeiro: Universidade do Estado do Rio de Janeiro, 2007.

e FILHO, D. S. Pensando sobre o lugar da avaliação na educação por competências. Rio de Janeiro: Centro de Estudos de Pessoal e Forte Duque de Caxias, 2013, p. 183-199. (Coletânea HUMANIS).

VALENTE, J. A., MORAN, J. M. Educação a distância. São Paulo: Summus, 2011.

VYGOTSKY, L. S. Pensamento e Linguagem. São Paulo: Martins Fontes, 1989.

A formação social da mente. São Paulo: Martins Fontes, 1991.

“Alguns equívocos na interpretação de seu pensamento”. Cadernos de Pesquisa, n. 81, p. 67-69, mai. 1992. 